\title{
\begin{tabular}{l|l} 
POLITIQUES \& & Politiques et management public
\end{tabular}

\section{Les internautes moteurs des processus d'adoption et développement de l'e-gouvernement : une étude sur les communes bretonnes}

Internet users leading adoption and diffusion of e-government: a study based on local government in Brittany

\section{Godefroy Dang Nguyena, Sylvain Dejean and Adrien Souquet}

\section{OpenEdition}

\section{Journals}

\section{Electronic version}

URL: http://journals.openedition.org/pmp/6336

ISSN: 2119-4831

Publisher

Institut de Management Public (IDPM)

\section{Printed version}

Date of publication: 1 January 2013

Number of pages: $29-49$

ISBN: 978-2-7430-1505-3

ISSN: 0758-1726

Electronic reference

Godefroy Dang Nguyena, Sylvain Dejean et Adrien Souquet, «Les internautes moteurs des processus d'adoption et développement de l'e-gouvernement : une étude sur les communes bretonnes »,

Politiques et management public [En ligne], Vol 30/1 | 2013, mis en ligne le 11 septembre 2015, consulté le 23 avril 2019. URL : http://journals.openedition.org/pmp/6336 
